\title{
A Linear Programming Model for Product Mix Profit Maximization in A Small Medium Enterprise Company
}

\author{
Safwa Mohd Baki', and Jack Kie Cheng1, \\ ${ }^{1}$ Faculty of Industrial Management, Universiti Malaysia Pahang, 26300 Pahang, Malaysia.
}

ABSTRACT - Production planning is often challenging for small medium enterprises (SMEs) company. Most of the SMEs are having difficulty in determining the optimal level of the production output which can affect their business performance. Product mix optimization is one of the main key for production planning. Many company have used linear programming model in determining the optimal combination of various products that need to be produced in order to maximize profit. Thus, this study aims for profit maximization of a SME company in Malaysia by using linear programming model. The purposes of this study are to identify the current process in the production line and to formulate a linear programming model that would suggest a viable product mix to ensure optimum profitability for the company. ABC Sdn Bhd is selected as a case study company for product mix profit maximization study. Some conclusive observations have been drawn and recommendations have been suggested. This study will provide the company and other companies, particularly in Malaysia, an exposure of linear programming method in making decisions to determine the maximum profit for different product mix.
ARTICLE HISTORY

Received: 30-11-2020

Accepted: 04-01-2021

KEYWORDS

Product Mix;

Linear Programming;

Small Medium Enterprise;

Drinking Water

\section{INTRODUCTION}

Every organization has its own goals and objectives to be accomplished in relation to the organization's mission and vision statement (Opoola, 2017). Naturally, the ultimate goal of every organization is to obtain a high profit. With globalization happening around the world that lead to increase competition among companies has become more challenging and has put tremendous pressure on company especially small medium enterprise in achieving their main goal. It is not sufficient for a company to gain competitive advantage and increase firm performance by only competing at firm level (Chew, 2018). As the business environment is unpredictable and changes rapidly, the company need to change and improve their operations and practices with new and more holistic organizational strategies that stretch from the supply level until to the end users.

In Malaysia, it is reported that there is a possibility of an economic slowdown since the government has not provided a clear direction in steering the economy forward (Tang, 2019). The possibility of slow-down in the economy has become the biggest concern among Malaysian SMEs, local large enterprises and multinational companies as it can affect the business performance (Tang, 2019). The economy slow-down will make it difficult for the company to predict the customer demands in terms of volume, product mix and time. The demand uncertainty can lead to high cost for the company due to increasing mismatch between demand and supply. Based on Biswas \& Chakraborty (2016), most of the SMEs do not have proper production planning and control due to lack of knowledge and expertise in that area, which results the inventory and other resources are not properly utilized. The management of SMEs always having difficulty in finding optimal levels of planning, organizing and controlling the production outputs. That is why the SMEs need to focus on their production planning and control which can improve their productivity and profit.

Small and medium sized enterprises (SMEs) play a crucial role in Malaysian economy. According to Department of Statistics Malaysia (2019), small and medium industry represents $98.5 \%$ of the total businesses in Malaysia. SME is one of the important sectors in Malaysia contributing RM 521.7 billion of the nation's gross domestic product (GDP) in 2018. Kamarudin (2019) reported that SMEs have helped in providing 5.7 million jobs to $70 \%$ of Malaysia's workforce. However, most of the SMEs are lack of holistic business process management which has prevented them from being in line and competing with the local large enterprise and multinational companies.

To be in competition, SMEs have to streamline the production activities and achieve maximum utilization of the firm resources to increase the productivity. Production planning and control is required in order to achieve effective resource utilization, to provide uninterrupted production process for diverse customer demand in relation to quality and timely delivery and to help the company to deliver a good products to customers on continuous basis at competitive rates (Biswas \& Chakraborty, 2016). One of the keys in production planning is the determination of the optimal product mix as it can impact the company's profitability. Product mix problem involves the selection of optimal product combinations that maximize profit in demand constraints and production resources (Gunasekaran, Zainali, \& Aghapour, 2015). By achieving an optimal product mix, the company is able to increase profits and minimize production costs. As stated by Ginting, 
Kirawan, \& Marpaung (2018), the company is able to increase $1.9 \%$ of net profit in production line through product mix optimization and reduce the production costs by $5 \%$ to $10 \%$. Thus, effective utilization of the firm's resources and increased production productivity can be achieved.

ABC Sdn Bhd is one of the SMEs in Malaysia. ABC Company often have an issue where sometimes they are unable to meet the customer demands in a timely manner due to lack of proper production planning and control. Due to that, the company is faced with inefficient utilization of resources that make it more difficult to determine the optimal product mix for maximum profit, which also to fulfil the customer needs. Therefore, the management of the company is always looking for ways to make informed decisions in finding out the optimal levels of their products that need to be produced and at the same time maximize the profitability of the company.

There are various theoretical and quantitative techniques have been developed to evaluate these decision problems. One of the techniques is linear programming model. The main purpose of this study is to observe current process in the production line of ABC Company for decision variables and constraints identification and to formulate a linear programming model that would suggest a viable product mix to ensure optimum profit for ABC Company. Specifically, to effectively estimate which products of $\mathrm{ABC}$ Company must be given more attention or produced more in other to maximize the profit. This study also will assist the management of ABC Company to make a better decision without wasting time and money.

\section{LITERATURE REVIEW}

\section{Concept of Linear Programming}

Linear programming (LP) is a mathematical techniques that aimed in optimizing performance in terms of combinations of resources (Yahya, Garba, \& Ige, 2012). According to Sharma (2016), linear programming is useful for the allocation of scarce or limited resources to several competing activities on the basis of given criterion of optimality. LP is also known as a mathematical technique to achieve profit maximization or cost minimization in a mathematical model whose requirements are represented by linear relationship (Gunasekaran et al., 2015).

Linear programming helped in making optimum use of productive resources (Ogbeide, 2018). Linear programming techniques also offers practical and viable solutions as there may be different constraints operating beyond the problem that need to be considered. It also helps in revising the fundamental plan for a variety of situations. If there is some changes on the conditions whether decision variables or constraints when the linear programming model is partially achieved, the model can be controlled by changing or altering the conditions for the optimal results (Ezema \& Amakom, 2012).

Linear programming is a mathematical technique that widely used in operation research or management science, in finding solutions to complex managerial decision problems that allows options between alternative courses of action (Yahya et al., 2012). Linear programming can be used in solving product mix problems, production planning problems, assembly line balancing problem, transportation and assignment problems. Linear programming can also be applied in other areas such as agricultural planning, farm management, selecting air weapon system, education, hospital administration and capital budgeting (Sharma, 2009).

\section{Structure of Linear Programming Model}

There are four basic elements or components of linear programming model that has been identified by Nahmias (2004) and Sharma (2009):

(i) Objective function:

Objective function of each LP problem is expressed in terms of decision variables to optimize the criterion of optimality profit, cost, revenue or distance amongst others. Objective function can be either maximization or minimization.

(ii) Decision variables:

Decision variables are mathematical symbols represent levels of activity by the firm. It also describes the quantities that the decision makers would like to determine. Typically, the value of the decision variables will be determined through an optimization method. Decision variables usually referred as $X_{1}, X_{2}, X_{3}, \ldots, X_{n}$. The decision variables are usually interrelated in terms of consumption of limited resources and also require simultaneous solutions. In a linear programming model, all decision variables are continuous, controllable and non-negative.

(iii) Constraints:

A LP model is a linear relationship that represents restrictions on decision making. The constraints can be in the form of restrictive guideline or limited resources such labour and machine. The solution of a linear programming model must satisfy the constraints.

(i) Linearity:

In term of linearity, optimization problems can be formulated as LP only when the objective can be expressed as a linear function of the decision variables and all constraints can be expressed as linear functions of the decision variables. 
According to (Molina, 2018), there are three steps in formulating linear programming model. The first step is to clearly define the decision variables and specify them as $X_{1}, X_{2}, X_{3}, \ldots, X_{n}$. The second step is identifying the objective function which is required to be maximized or minimized and express it in terms of the predefined decision variables, $\mathrm{z}=$ $\mathrm{f}(\mathrm{x})$. The third step is to identify all the constraints and translate them into linear inequalities in terms of the pre-defined decision variables.

The simplest form of linear programming model for profit maximization is:

$$
\text { Maximize } Z=P_{1} X_{1}+P_{2} X_{2}
$$

Subject to:

$$
\begin{aligned}
& A_{1} X_{1}+A_{2} X_{2}<=\mathrm{C} 1 \\
& A_{3} X_{1}+A_{4} X_{2}<=\mathrm{C} 2
\end{aligned}
$$

$\mathrm{Z}$ denotes as the total profit, $P_{1}$ and $P_{2}$ are profit contribution coefficients expressing per unit contribution to the profit equation, $X_{1}$ and $X_{2}$ are the decision variables. $\mathrm{C}$ is the constraints of resource values which available and $\mathrm{A}$ is the numerical values that expressed in per unit usage of the decision variables. Constraints can be expressed as equations (=) or inequalities $(\geq$ or $\leq)$. Strict inequalities such as " $>$ " or " $<$ " are not allowed as it may lead to vague problems (Molina, 2018). The linear programming model can be in mathematical form either for minimization or maximization (Haider et al., 2016).

\section{Product Mix Optimization}

Product mix is also known as product assortment, which set of product items that a particular seller or manufacturer offers for sale to the buyers. Product mix strategy plays an important role in the manufacturing sector (Gunasekaran et al., 2015). The management especially in a multi-product company often faced an allocation problem, where they have difficulty in finding the right amount of each product to be produced under the given constraints of the organization so that overall efficiency and profit can be maximized (Ezema \& Amakom, 2012). This is also known as an optimization problem and can be solved through optimal product mix technique. Product mix adjustments can assist the managers to increase the profitability by focusing more on producing high profit products. The optimal product mix enables the managers to solve major problems of maximizing profit and minimizing cost (Ogbeide, 2018).

Linear programming (LP) is a mathematical method that used in seeking for the ideal strategy in any decision situation under the restriction of limited resources and uncertainties (Ogbeide, 2018). Linear programming is a subset of mathematical programming that is concerned with efficient allocation of limited resources to known activities with the objective of meeting a desired goal of maximization of profit or minimization of cost (Taha, 2011). LP is a tool for optimizing decision-making process and it is used for solving a broad class of optimization problems. As the company strive to achieve optimal performance by maximizing profits or minimizing costs, they can expect the best results with this optimization technique.

Besides, linear programming is the most prominent technique in operational research technique for solving optimization problems. Linear Programming is a model that consists of linear relationship represents the firm's decisions, given an objective and available constraints (Ezema \& Amakom, 2012). Most of the researchers have used linear programming techniques for product mix problems in their study (Muda, 2015) (Alagoz, Dundar, \& Bezirci, 2012) (Sengupta, 2016). Fagoyinbo, Akinbo, Ajibode, \& Olaniran (2010) have investigated the maximization of profit in manufacturing industries using linear programming technique in Geepee Nigeria Limited. Balogun, Jolayemi, Akingbade, \& Muazu (2012) also used linear programming technique to derive the maximum profit from production of soft drink for Nigeria Bottling Company Nigeria, Ilorin plant.

Most of the researchers also have formulated a linear programming model with the objective function to maximize profit under the capacity constraint, demand constraint and raw materials availability (Wang \& Li, 2017). In product mix problem, demand, cost and resource capacity are the most used constraints in the studies. In term of resource capacity, raw material availability and machine capacity are usually being considered in previous studies (Haider et al., 2016). From the previous research, it has helped the decision makers in the company in making decision for their production planning where they focusing more on high-sales products for their production (Maurya, Misra, Anderson, \& Shukla, 2015). 


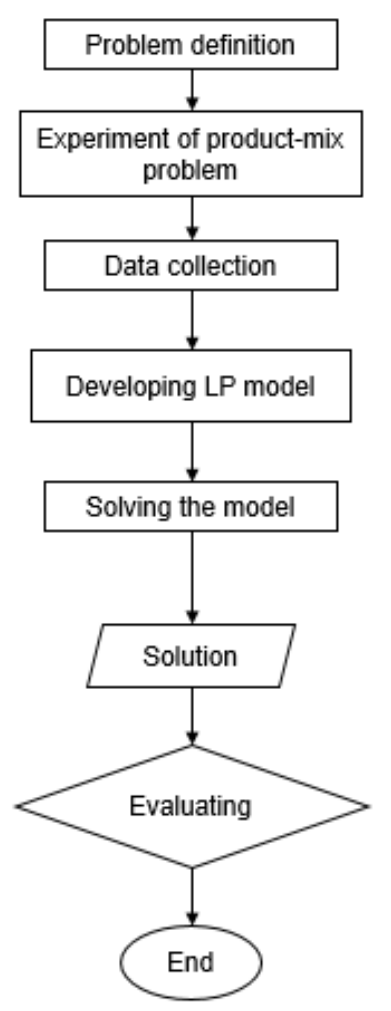

Figure 3.1 Research Procedure

Figure 3.1 above shows the procedures involved for this study. The first step is to identify a related problem in the study area by investigating and defining the identified problem. Then, a research on similar previous studies regarding the product mix problems and their proposed solutions have been studied in order to identify the best solving method for this problem. For this study, a case company is selected and primary and secondary data collection method has been used in order to gather relevant data from the company. Figure 3.2 below shows the flow chart of constructing a linear programming model. To identify the decision variables, objective functions and constraints of the company, observation on the production line process and an interview session with the manager and production supervisor of ABC Company has been conducted. And additional secondary data sources were used to get accurate information. Then, the data collected were analysed to develop a LP model. QM for Windows software is used to solve the linear programming model. The QM for Windows software was preferred for accuracy purpose. By studying the solution and determining the optimal product-mix for profit maximization are considered as the solution step. Finally, the proposed solution from QM Solver is evaluated by comparing the results to the actual data and sensitivity analysis can be performed.

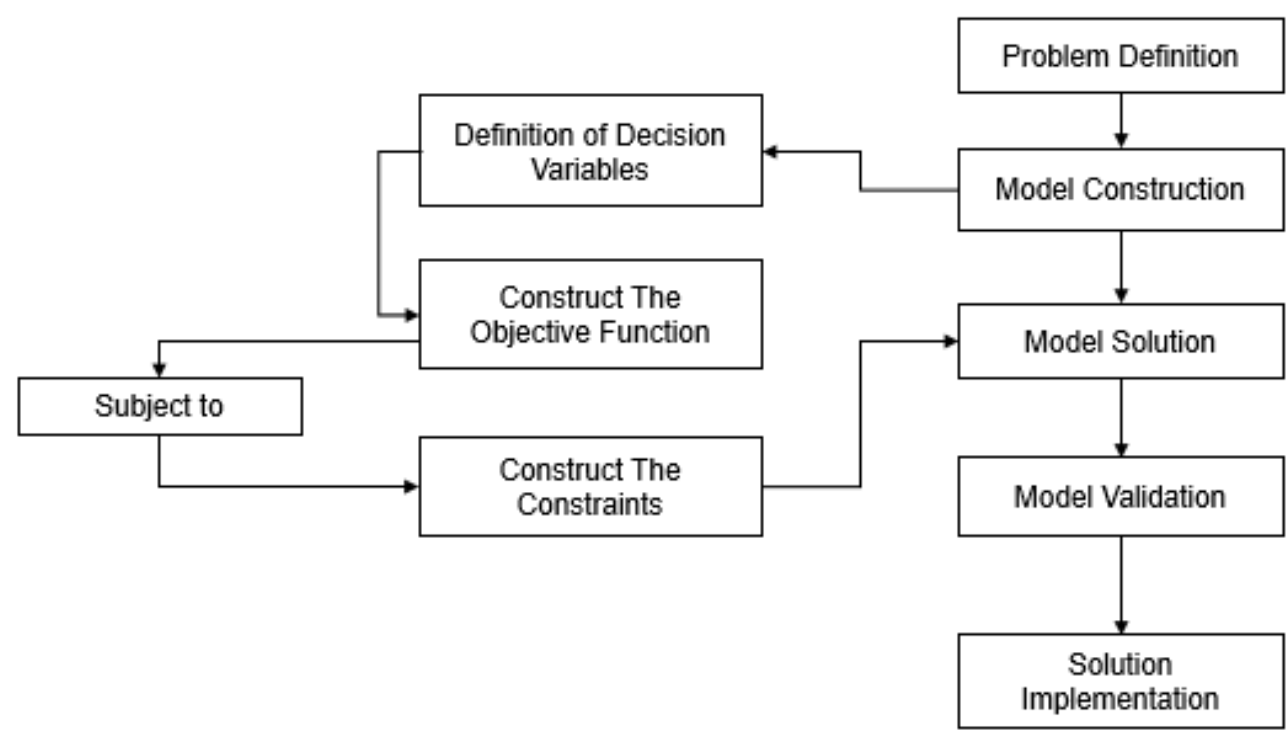

Figure 3.2 Flow Chart illustrates Construction of Linear Programming Model 


\section{The Company Case}

This study is conducted at ABC Sdn Bhd. ABC Sdn Bhd is a small medium enterprise (SME) company which located in Pahang, Malaysia. This company was established on 2004. ABC Sdn Bhd is a drinking water manufacturing company. There are four main products of ABC Sdn Bhd; Drinking Water 5500ml, Drinking Water 1500ml, Drinking Water 500ml and Drinking Water $250 \mathrm{ml}$. Other than that, ABC Sdn Bhd also produces drinking water $(5500 \mathrm{ml}, 1500 \mathrm{ml}, 500 \mathrm{ml}$ and $250 \mathrm{ml}$ ) for another brands. The products of ABC Sdn Bhd are distributed all around Malaysia. However, ABC Company confronted an issue with inefficient utilization of resources due to lack of production planning and control which has affected the timely delivery for the customers. That is why the management of the company wants to make a better decision to improve the productivity of the company so that they can better compete in a competitive market.

This study will focus on two major products of ABC Sdn Bhd which are Drinking Water 1500ml and Mineral Water 500ml. Figure 4.1 below shows sales of each product in ABC Sdn Bhd in Year 201X. Drinking Water 500ml and Drinking Water $1500 \mathrm{ml}$ are selected as these two products have generated high number of sales for the company. Even though, there is a slightly different of sales between Drinking Water 5500ml and Drinking Water 500ml, the Drinking Water $5500 \mathrm{ml}$ cannot be chosen as one of the decision variables for the LP model due to the different production process of Drinking Water $5500 \mathrm{ml}$ with Drinking Water $500 \mathrm{ml}$ and Drinking Water $1500 \mathrm{ml}$.

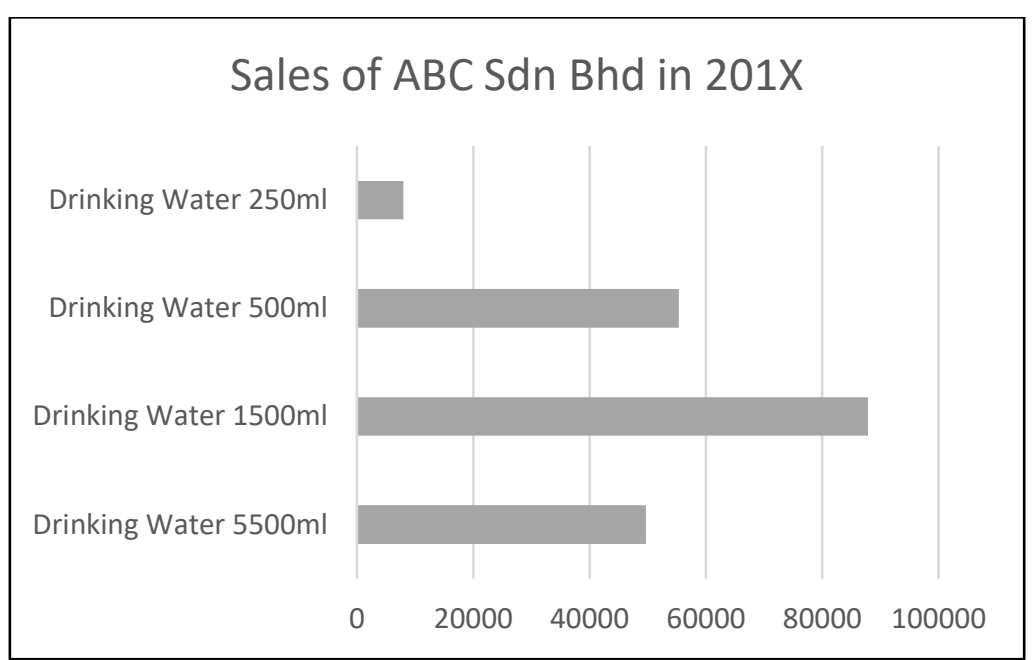

Figure 4.1 Sales of ABC Sdn Bhd in Year 201X

Figure 4.2 below shows the production process of ABC Sdn Bhd while Figure 4.3 below shows the production layout of ABC Sdn Bhd. In ABC Company, there are three production process which are dryer process, machine process and packaging process. All products except Drinking Water $5500 \mathrm{ml}$ undergo the same production process.

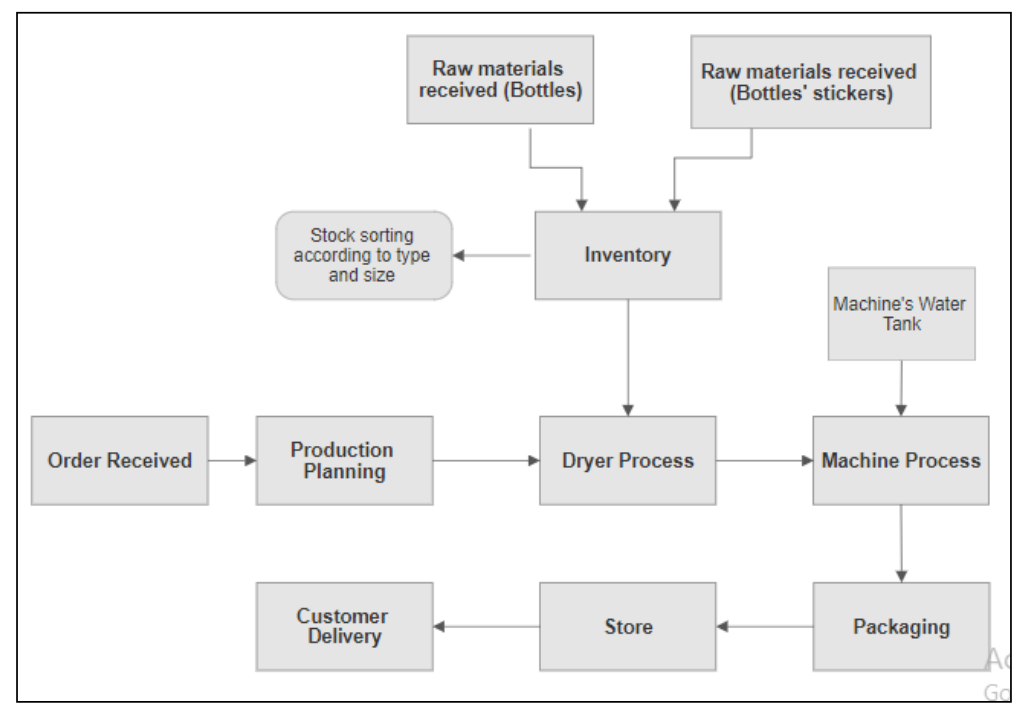

Figure 4.2 Production Process of ABC Sdn Bhd 


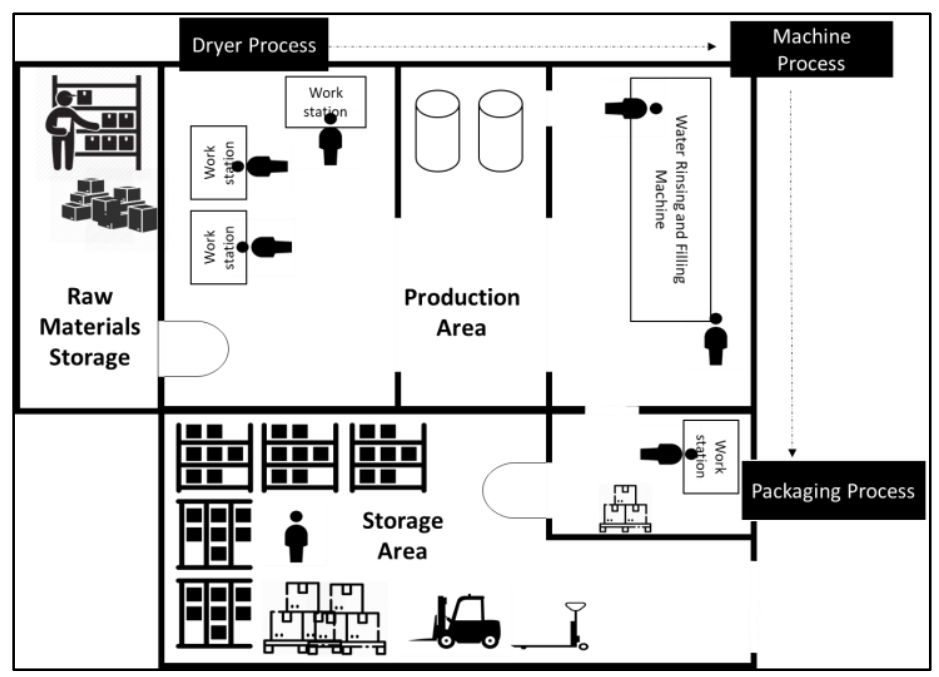

Figure 4.3 Production Layout of ABC Sdn Bhd

From the observation in the production process of this company, findings or data regarding the decisions variables and constraints have been identified. The data for the constraints is summarised in tables below. Table 4.1 shows the resources available every day for the production process. Table 4.2 shows the production details for each decision variable per box (Drinking Water 1500ml and Drinking Water 500ml) in term of its profit, amount of water and processing time.

Table 4.1 Resources Availability for Daily Production in ABC Sdn Bhd

\begin{tabular}{lr}
\hline & Resources available per day \\
& \\
\hline Machine capacity & 30,000 bottles \\
\hline Water resource & 27,000 litres \\
\hline Production available & $1,350 \mathrm{~min}$ \\
\hline
\end{tabular}

Machine capacity is referred to the capacity of the machine in producing the drinking water in unit of bottle for $500 \mathrm{ml}$ and $1500 \mathrm{ml}$. In a day, the machine can only produce 30,000 bottles for Drinking Water 500ml and Drinking Water $1500 \mathrm{ml}$. Water resource is the amount of water (in litre) that the company will pump for the production process. The company will pump 27,000 litres of water for their production. Production available is referred to the operating time of the machine. In a day, the machine can be operated for 1,350 minutes only where the machine need to be rested for 90 minutes.

Table 4.2 Production Details of Drinking Water 1500ml and Drinking Water 500ml

\begin{tabular}{lcrr}
\hline Product & Bottles & $\begin{array}{r}\text { Amount of Water } \\
\text { (litre) }\end{array}$ & Processing time (min) \\
\hline Drinking Water $1500 \mathrm{ml}$ & 12 bottles & $18 \mathrm{~L}$ & 0.75 \\
\hline Drinking Water $500 \mathrm{ml}$ & 24 bottles & $12 \mathrm{~L}$ & 0.8 \\
\hline
\end{tabular}

ABC Company sold their products in unit of box where ABC Company will earn profit of RM4 for each box of Drinking Water $1500 \mathrm{ml}$ and RM3 for each box of Drinking Water 500ml. For each box of Drinking Water 1500ml, there are 12 bottles of $1500 \mathrm{ml}$, the total amount of water per box is 18 litres and the processing time is 0.75 minutes. There are 24 bottles of $500 \mathrm{ml}$ in each box of Drinking Water $500 \mathrm{ml}$, the amount of water per box is 12 litres and the processing time is 0.8 minutes. Based on the data above, it shows that the company did not fully utilized their resources effectively and it can be considered as waste for the company. 


\section{RESULTS AND DISCUSSION}

Based on the information and data collected, a linear programming model is formulated as follow:

Step 1: This study is to determine the number of each product that need to be produced, which led to the following definition of decision variables:

$$
\begin{aligned}
& X_{1}=\text { number of Drinking Water } 1500 \mathrm{ml} \text { to be produced } \\
& X_{2}=\text { number of Drinking Water } 500 \mathrm{ml} \text { to be produced }
\end{aligned}
$$

Step 2: Objective Function. The objective function for this study is to maximize (optimum) profit of ABC Sdn Bhd per day.

$$
\text { Maximize } Z=4 X_{1}+3 X_{2}
$$

Step 3: There are three constraints identified in this study:

Constraint based on machine capacity

$$
12 X_{1}+24 X_{2}<=30,000 \text { bottles }
$$

Constraint based on water resource

$$
18 X_{1}+12 X_{2}<=27,000 \text { litres }
$$

Constraint based on production available

$$
0.75 X_{1}+0.8 X_{2}<=1,350 \text { minutes }
$$

Non-negativity constraint

$$
X_{1}, X_{2}>=0
$$

The non-negativity constraint is to ensure that ABC Company will not able to produce zero amount of Drinking Water $1500 \mathrm{ml}$ and Drinking Water $500 \mathrm{ml}$ per day. Therefore, the linear programming model of profit maximization for this study is:

Subject to:

$$
\text { Maximize } Z=4 X_{1}+3 X_{2}
$$

$$
\begin{gathered}
12 X_{1}+24 X_{2}<=30,000 \text { bottles } \\
18 X_{1}+12 X_{2}<=27,000 \text { litres } \\
0.75 X_{1}+0.8 X_{2}<=1,350 \text { minutes } \\
X_{1}, X_{2}>=0
\end{gathered}
$$

Based on the solution from QM for Windows, ABC Sdn Bhd is suggested to produce 1000 boxes of Drinking Water $1500 \mathrm{ml}\left(X_{1}\right)$ and 750 boxes of Drinking Water $500 \mathrm{ml}\left(X_{2}\right)$ in order to get an optimum profit of RM 6,250.00 per day as shown in Table 5.1 below. 
Table 5.1 QM Reports of Original Problems with Answer

$\begin{array}{llll}\mathrm{X} 1 & \mathrm{X} 2 & \text { RHS }\end{array}$

\begin{tabular}{|c|c|c|c|c|c|}
\hline Maximize & 4 & 3 & & & \\
\hline Machine & 12 & 24 & $<=$ & 30000 & .0208 \\
\hline \multicolumn{6}{|l|}{ Capacity } \\
\hline Water Resource & 18 & 12 & $<=$ & 27000 & .2083 \\
\hline Production & .75 & .8 & $<=$ & 1350 & 0 \\
\hline Solution-> & 1000 & 750 & Optimal Z-> & 6250 & \\
\hline
\end{tabular}

Table 5.2 QM Report of Ranging

\begin{tabular}{|c|c|c|c|c|c|}
\hline Variable & Value & Reduced Cost & Original Val & $\begin{array}{l}\text { Lower } \\
\text { Bound }\end{array}$ & $\begin{array}{l}\text { Upper } \\
\text { Bound }\end{array}$ \\
\hline $\mathrm{X} 1$ & 1000 & 0 & 4 & 1.5 & 4.5 \\
\hline $\mathrm{X} 2$ & 750 & 0 & 3 & 2.6667 & 8 \\
\hline Constraint & Dual Value & Slack/Surplus & Original Val & $\begin{array}{l}\text { Lower } \\
\text { Bound }\end{array}$ & $\begin{array}{l}\text { Upper } \\
\text { Bound }\end{array}$ \\
\hline $\begin{array}{l}\text { Machine } \\
\text { Capacity }\end{array}$ & .0208 & 0 & 30000 & 18000 & 30000 \\
\hline Water Resource & .2083 & 0 & 27000 & 15000 & 27000 \\
\hline Production & 0 & 0 & 1350 & 1350 & Infinity \\
\hline
\end{tabular}

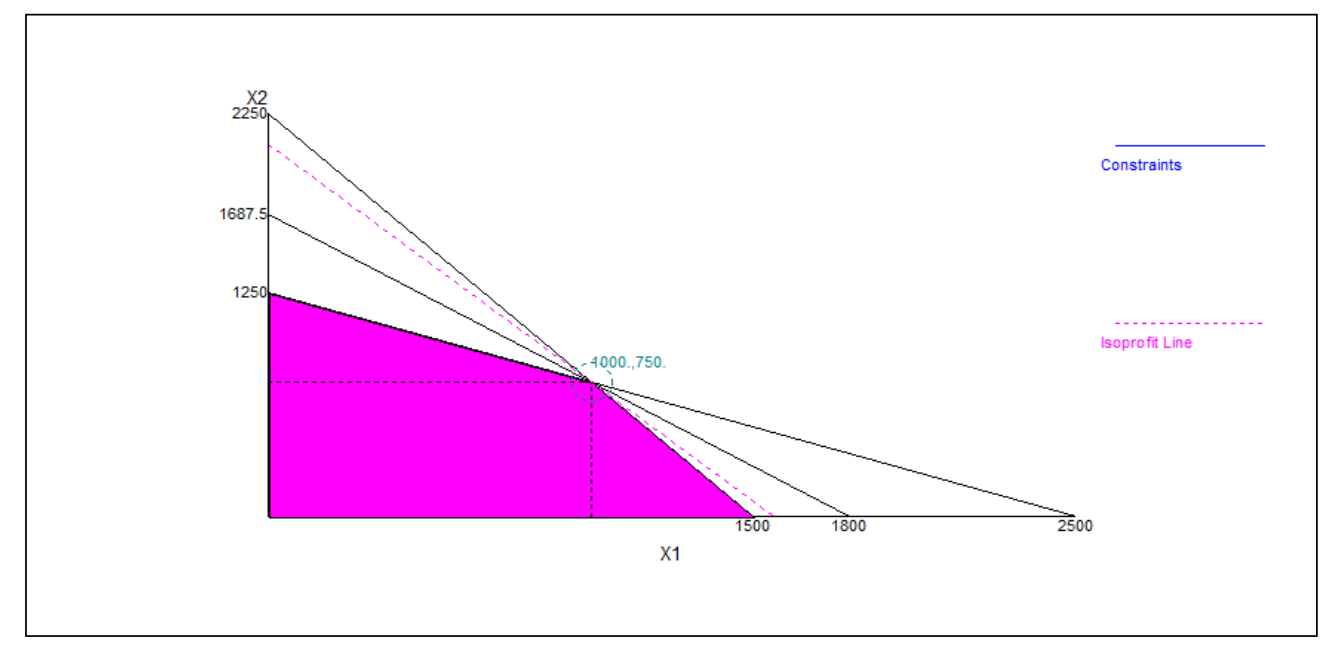

Figure 5.1 Graph of QM Solver Solution

A sensitivity analysis can be carried out based on the optimal solution as shown in Table 5.1 and Table 5.2. The dual value of the model constraints in Table 5.2 indicates that the profit ( $\mathrm{Z}$ value) will increase if the allocation for the constraint is increased by one unit. For example, if the machine capacity is increase by one unit, it can add RM 0.0208 more to the profit without changing the current basis optimal product mix. Other than that, the decision maker of the company also need to know the allowable amount that they can allocate for the resources without changing current optimal solution. This information is shown in the lower bound and upper bound of the constraints, mentioned in Table 5.2 above. 
The lower bound and upper bound refer to the allowable increase and allowable decrease amount for the constraints that the decision maker can allocate with current solution remains optimal.

As example, for the constraint of the machine capacity, the current solution will remains optimal if the machine capacity is decreased by up to 18000 (the lower bound) or increased by up to 30000 (the upper bound). The information provided by QM Solver can be used as a guideline for the management in deciding whether to increase or decrease the amount of production resources such as the machine capacity and water resource.

Table 5.3 below shows current production output of ABC Sdn Bhd per day and profit earned per day and per month for both products. Currently, the average amount of Drinking Water 1500ml produced per day is 564 boxes and the average amount of Drinking Water $500 \mathrm{ml}$ produced per day is 552 boxes. From this production output, the company earned in total RM 3,912 per day and RM 117,360 per month for both product. However, by using linear programming solution, it is suggested that the company to produce 1000 boxes of Drinking Water $1500 \mathrm{ml}$ and 750 boxes of Drinking Water $500 \mathrm{ml}$ per day in order to get an optimum profit of RM 6,250.00 per day. In a month, the company is able to earn RM 187,500 for both products as shown in Table 5.4 below. There are $59.76 \%$ increase from current profit to the optimum profit.

Table 5.3 Current production output of ABC Sdn Bhd

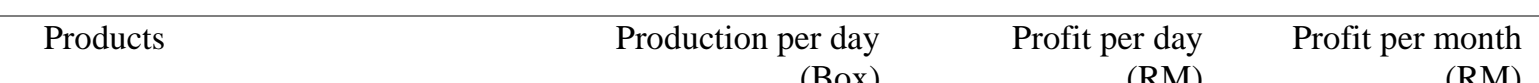

\begin{tabular}{lrrr}
\hline Drinking Water $1500 \mathrm{ml}$ & 564 & 2256 & 67680 \\
\hline Drinking Water $500 \mathrm{ml}$ & 552 & 1656 & 49680 \\
\hline Total & 1116 & RM3,912.00 & RM117,360.00 \\
\hline
\end{tabular}

Table 5.4 Suggested optimal solution for production output of ABC Sdn Bhd

\begin{tabular}{lrrr}
\hline Products & $\begin{array}{r}\text { Production per day } \\
\text { (Box) }\end{array}$ & $\begin{array}{r}\text { Profit per day (RM) } \\
\text { Profit per month } \\
(\mathrm{RM})\end{array}$ \\
\hline Drinking Water $1500 \mathrm{ml}$ & 1000 & 4000 & 120000 \\
\hline Drinking Water $500 \mathrm{ml}$ & 750 & 2250 & 67500 \\
\hline Total & 1750 & RM6,250.00 & RM187,500.00 \\
\hline
\end{tabular}

This optimal solution helps the company in fully utilized all the resources efficiently. By producing according to the optimal solution, the company will be able to meet the customer demand in a timely manner and also the company will able to handle the uncertain demand effectively.

\section{CONCLUSION}

This study focused on a small medium enterprise company as a case study with the aim of applying linear programming for product mix optimization. This study has developed a linear programming model by identifying the objective function, decision variables, and constraints through understanding of the current production line of the company which is fulfilled the objective 1. Based on the solution from QM for Windows, it is suggested that the company should produce 1000 boxes of Drinking Water $1500 \mathrm{ml}$ and 750 boxes of Drinking Water 500ml. Hence, by producing this amount of product per day, the company will be able to earn RM 6,250 per day and RM 187,500 per month which has fulfilled objective 2 and 3. This study will help the company to make a better decision for their production planning and to fully utilize all the resources available in order to get a maximum profit.

However, there are several limitations for this study. The linear programming model provides a snapshot for current situation in the company and it cannot be used for forecasting the production capacity and sales volume of the company. The entire model of linear programming also need to be changed if new constraints or decision variables are added. Besides that, demand constraint should be included in this study as it can affect the production as well.

This company relies solely on trial and error method, although the company has the opportunity to use any mathematical or statistical models for forecasting their production or sales as there is a record for their annual production and sales. Therefore, it is recommended for the company to use hybrid method such as simulation and linear programming model for forecasting the production capacity. This study will give exposure for the decision maker of the company to change to model based decision making process. This is because the model based decisions are more accurate and objective. So, the company should continue using linear programming method and explore the possibility of using linear programming such as for cost minimization 


\section{REFERENCES}

Alagoz, A., Dundar, A. ., \& Bezirci, M. (2012). Determining the Product Mix that Maximizes Profitability: A Sample Model Belonging to a Flour Mill. International Business Management, 6.

Balogun, O. ., Jolayemi, E. ., Akingbade, T. ., \& Muazu, H. . (2012). Use Of Linear Programming For Optimal Production In A Production Line In Use Of Linear Programming For Optimal Production In A Production Line In Coca - Cola Bottling Company , Ilorin. International Journal of Engineering Research and Applications (IJERA), 2(5).

Biswas, S., \& Chakraborty, A. (2016). Importance of Production Planning and Control in Small Manufacturing Enterprises, 5(6), 6164.

Chew, L. L. (2018). Competitive Advantage of Malaysian Small Medium Enterprises: Impact of Supply Chain Management Practices, Environmental Uncertainty and Supply Chain Flexibility, (July).

Ezema, B. I., \& Amakom, U. (2012). Optimizing Profit with the Linear Programming Model: A Focus on Golden Plastic Industry Limited, Enugu, Nigeria. Interdisciplinary Journal of Research in Business, 2(2), 2046-714137.

Fagoyinbo, I. ., Akinbo, R. ., Ajibode, I. ., \& Olaniran, Y. O. . (2010). Maximization of Profit in Manufacturing Industries using Linear Programming Techniques: GeePee Nigeria Limited. African Society for Scientific Research (ASSR) MAXIMIZATION.

Ginting, M., Kirawan, M., \& Marpaung, B. (2018). Product mix optimization on production planning-a Fuzzy Mixed Integer Linear Goal Programming ( FMILGP) approach : A single case study, 02004.

Gunasekaran, H. L., Zainali, S., \& Aghapour, A. H. (2015). The Optimization Problem of Product-Mix and Linear Programing Applications ; A single-Case Study in Tea Industry. Australian Journal of Basic and Applied Sciences, 9(3), 7-18.

Haider, Z., Fareed, R., Tariq, M. B., Usman, S., Ud din, N., \& Khan, S. (2016). Application of Linear Programming for Profit Maximization : A Case of Paints. International Journal of Management Sciences and Business Research, 5(12), $144-151$.

Kamarudin, K. (2019, April 29). Rev Up SME Sector To Create More Jobs: Economist. Bernama.Com.

Malaysia, D. of S. (2019). SME Landscape of Malaysia.

Maurya, V. N., Misra, R. B., Anderson, P. K., \& Shukla, K. K. (2015). Profit Optimization Using Linear Programming Model : A Case Study of Ethiopian Chemical Company. American Journal of Biological and Environmental Statistics, 1(2), 51-57. https://doi.org/10.11648/j.ajbes.20150102.12

Molina, M. G. (2018). International Journal of Applied Mathematics Electronics and Computers Product Mix Optimization at Minimum Supply Cost of an Online Clothing Store using Linear Programming, 6(3), 33-38. https://doi.org/10.1039/b000000x

Muda, N. (2015). Determination of optimum values for maximizing the profit in bread production Determination of optimum values for maximizing the profit in bread production : Daily bakery Sdn Bhd, (February). https://doi.org/10.1063/1.4907528

Nahmias, S. (2004). Production and Operation Analysis (5th Editio). Mcgraw-Hill College;

Ogbeide, D. (2018). Product Mix Optimization in the Manufacturing Industry: A Linear Product Mix Optimization in the Manufacturing Industry : A Linear Programming Approach, (December).

Opoola, O. M. (2017). Inventory Control and Profit Maximization in A Manufacturing Company; A Case Study of Nigeria Distrilleries Limited, Sango Otta Ogun State, (October).

Sengupta, D. (2016). Determination of Optimal Product Mix for Profit Maximization using Linear Programming. JERA, 6(1).

Sharma, J. . (2016). Operations research: theory and applications (6th Editio). New Delhi: Trinity Press, an impint of Laxmi Publications Pvt. Ltd.

Taha, H. A. (2011). Operations Research: An Introduction (9th Editio). Prentice Hall.

Tang, A. (2019, May 2). Businesses worry about economy slowing, uncertain government policies. The Star Online. Retrieved from thestar.com.my/news/nation/2019/05/02/businesses-worry-about-economy-slowing-uncertain-govt-policies

Wang, Y., \& Li, L. (2017). Computers \& Industrial Engineering Manufacturing profit maximization under time-varying electricity and labor pricing. Computers \& Industrial Engineering, 104, 23-34. https://doi.org/10.1016/j.cie.2016.12.011

Yahya, W. B., Garba, M. K., \& Ige, S. O. (2012). Profit Maximization In A Product Mix Company Using Linear Programming, 4(17), 126-131. 